OPEN ACCESS

Edited by:

Casper J. Van Der Kooi, University of Groningen, Netherlands

Reviewed by:

David Pritchard,

University of Stirling, United Kingdom Nigel E. Raine,

University of Guelph, Canada

${ }^{*}$ Correspondence:

Sarah K. Richman

sarahkrichman@gmail.com

Specialty section:

This article was submitted to Behavioral and Evolutionary Ecology,

a section of the journal

Frontiers in Ecology and Evolution

Received: 20 April 2021

Accepted: 23 September 2021

Published: 15 October 2021

Citation:

Richman SK, Barker JL, Baek M Papaj DR, Irwin RE and Bronstein JL (2021) The Sensory and Cognitive Ecology of Nectar Robbing. Front. Ecol. Evol. 9:698137. doi: 10.3389/fevo.2021.698137

\section{The Sensory and Cognitive Ecology of Nectar Robbing}

\author{
Sarah K. Richman ${ }^{1,2 *}$, Jessica L. Barker,3,4, Minjung Baek ${ }^{5}$, Daniel R. Papaj ${ }^{5}$, \\ Rebecca E. Irwin ${ }^{6}$ and Judith L. Bronstein ${ }^{5}$ \\ ${ }^{1}$ Department of Biology, University of Nevada, Reno, Reno, NV, United States, ${ }^{2}$ Department of Environmental Systems \\ Science, ETH Zürich, Zurich, Switzerland, ${ }^{3}$ Interacting Minds Centre, Aarhus University, Aarhus, Denmark, ${ }^{4}$ Division \\ of Public Health, Alaska Department of Health and Social Services, Juneau, AK, United States, ${ }^{5}$ Department of Ecology \\ and Evolutionary Biology, University of Arizona, Tucson, AZ, United States, ${ }^{6}$ Department of Applied Ecology, North Carolina \\ State University, Raleigh, NC, United States
}

Animals foraging from flowers must assess their environment and make critical decisions about which patches, plants, and flowers to exploit to obtain limiting resources. The cognitive ecology of plant-pollinator interactions explores not only the complex nature of pollinator foraging behavior and decision making, but also how cognition shapes pollination and plant fitness. Floral visitors sometimes depart from what we think of as typical pollinator behavior and instead exploit floral resources by robbing nectar (bypassing the floral opening and instead consuming nectar through holes or perforations made in floral tissue). The impacts of nectar robbing on plant fitness are well-studied; however, there is considerably less understanding, from the animal's perspective, about the cognitive processes underlying nectar robbing. Examining nectar robbing from the standpoint of animal cognition is important for understanding the evolution of this behavior and its ecological and evolutionary consequences. In this review, we draw on central concepts of foraging ecology and animal cognition to consider nectar robbing behavior either when individuals use robbing as their only foraging strategy or when they switch between robbing and legitimate foraging. We discuss sensory and cognitive biases, learning, and the role of a variable environment in making decisions about robbing vs. foraging legitimately. We also discuss ways in which an understanding of the cognitive processes involved in nectar robbing can address questions about how plant-robber interactions affect patterns of natural selection and floral evolution. We conclude by highlighting future research directions on the sensory and cognitive ecology of nectar robbing.

Keywords: cognition, foraging, nectar robbing, pollination, plant reproduction, sensory ecology

\section{INTRODUCTION}

Plant-pollinator mutualisms involve cooperation by each partner but are rife with conflict as well. Although plants and pollinators rely upon one another for reproduction and food resources, respectively, the strategies used by each to maximize fitness are often at odds. Floral nectar, for example, is a carbohydrate-rich reward for pollinators, but functions to attract foragers and direct their activities in a way that benefits plants but not necessarily foragers (Pyke, 2016; van der Kooi et al., 2021). For instance, plants may produce many flowers, each with a small amount of nectar, 
to promote multiple visits, even though this may be less efficient for the pollinator (Belsare et al., 2009; Lichtenberg et al., 2020a). This conflict has made plant-pollinator interactions an ideal system to investigate mutualism, with many studies quantifying the relative costs and benefits for the pollinator and the plant.

A subset of the pollination literature focuses on nectar robbing, a floral foraging behavior with wide-ranging reproductive effects on plants (Inouye, 1980; Irwin et al., 2010). While many floral visitors insert their mouthparts through the floral opening to access nectar, often pollinating in the process (a behavior referred to hereafter as "legitimate" foraging), nectar robbers handle flowers in ways that make pollination less likely. Primary robbers make holes or slits in flowers through which they consume nectar, whereas secondary robbers consume nectar through existing holes (Inouye, 1980). The majority of nectar robbing studies focus on bees, but a wide variety of taxa, including birds and mammals, have been reported as nectar robbers (Irwin et al., 2010). Almost all plant species with hidden or recessed nectar in tubular corollas or spurs experience nectar robbing, with up to $100 \%$ of flowers robbed per plant (Irwin and Maloof, 2002). Given the ubiquity of the behavior, as well as the breadth in taxonomy and breeding systems of plants that are robbed, nectar robbing has the potential to strongly influence the ecology and evolution of pollination mutualisms.

Both plant ecologists and behavioral ecologists have studied nectar robbing; however, their respective foci and research questions have overlapped relatively little. The majority of nectar-robbing studies have taken the plant's perspective, testing the effects of nectar-robbing on plant individuals and populations, exploring the direct and pollinator-mediated indirect mechanisms by which those effects occur, and investigating the community contexts that affect robbing frequencies (Irwin et al., 2010; Rojas-Nossa et al., 2016; Fitch and Vandermeer, 2020). In contrast, a small but growing body of research on nectar robbing has taken the animal's perspective (Bronstein et al., 2017; Table 1). This work focuses primarily on the costs and benefits of robbing behavior to the forager itself, quantified in terms of energetics (Dedej and Delaplane, 2005; Zhang et al., 2011; Hazlehurst and Karubian, 2018). Findings point to some floral visitor-plant combinations in which robbing is more energetically profitable for the visitor than is legitimate visitation, and to other visitor-plant combinations that show the reverse (Lichtenberg et al., 2018).

Studies of nectar robbing that have taken the floral visitor's perspective have generally not considered the cognitive mechanisms that underlie visitors' foraging decisions (but see, e.g., Leadbeater and Chittka, 2008; Barker et al., 2018; Table 1). For example, while there are many reports in the literature of bees using a mix of robbing and legitimate foraging tactics (Figure 1), and while work has investigated the role of competition in tactic choice (Lichtenberg et al., 2020b), the cognitive mechanisms underlying these behaviors are largely unknown. We argue here that a deeper exploration into the sensory and cognitive processes involved in nectar robbing is needed to gain insight into the ecological and evolutionary causes of the behavior, as well as its consequences for plants. Toward this end, we can appeal to a growing literature on sensory and cognitive ecology, including a substantial body of work focusing on pollinator behavior (Chittka and Thomson, 2001; Schiestl and Johnson, 2013; Baracchi, 2019; Lihoreau et al., 2019; van der Kooi et al., 2021). This work has made significant inroads into characterizing the mechanisms that govern decision-making by floral visitors. We argue that it can be applied to nectar robbing as well as legitimate visitation.

Here, we extend the pollinator behavior literature to consider the sensory and cognitive processes that underlie nectar robbing. In doing so, we highlight ways in which variation across the floral resource landscape, such as in nectar standing crop, may promote or discourage nectar robbing behavior. We also discuss how incorporating sensory and cognitive biology into theoretical and empirical research frameworks can benefit plant evolutionary ecologists studying nectar robbing. Throughout this review, we highlight critical gaps in knowledge awaiting exploration, and we conclude by featuring two promising directions for future research.

\section{WHAT SENSORY AND COGNITIVE PROCESSES ARE INVOLVED IN NECTAR ROBBING?}

Floral visitors seeking nectar are bombarded by sensory information about their foraging environment. An individual visitor is presented with an array of floral traits that vary both within and among plant species and must choose a rewarding option. The challenge for foragers, given the onslaught of information they receive, is to integrate across sensory modalities to perceive and process their environment, and to make decisions about how and where to forage (i.e., perform cognitive functions; Webb, 2012). The task of finding floral rewards is complicated by the fact that floral traits can vary with the environment. For example, abiotic conditions such as water availability may alter a flower's scent profile or the volume or concentration of nectar (Parachnowitsch et al., 2019). Further, over the course of the day, flowers are asynchronously drained of nectar by other foragers, erasing nectar standing crop differences that might have existed among flowers earlier in the day (Lichtenberg et al., 2020a). A fluctuating environment requires foragers to rely on innate sensory biases, and ultimately make decisions based on experience and learning (Lichtenberg et al., 2020a). We first discuss such biases. Second, we discuss learning by floral visitors, and how primary and secondary nectar robbers might learn these foraging behaviors. Finally, we explore how innate and learned behaviors ultimately affect decision-making, highlighting ways that environmental variation can complicate the decision-making process and/or require more complicated exercises, such as task switching. We focus here primarily on bees, as their behavior in the context of decisions to nectar-rob has been studied in the greatest detail.

\section{Sensory Biases of Floral Visitors}

Naïve animals possess evolved, innate sensory responses that form a foundation for higher-level cognitive functioning (Webb, 2012). The pollination literature has extensively documented sensory biases of floral foragers. For example, naïve Bombus 
TABLE 1 | Sensory and cognitive processes involved in nectar robbing, including predictions, key findings and citations.

\begin{tabular}{|c|c|c|c|c|}
\hline $\begin{array}{l}\text { Sensory/cognitive } \\
\text { process }\end{array}$ & $\begin{array}{l}\text { Factors that might affect } \\
\text { process }\end{array}$ & Predictions & Exemplar studies & Citations \\
\hline $\begin{array}{l}\text { Sensory bias } \\
\text { (innate preference) }\end{array}$ & $\begin{array}{l}\text { Floral traits, Forager } \\
\text { evolutionary history }\end{array}$ & $\begin{array}{l}\text { Floral signals will not match sensory } \\
\text { biases of nectar robbers. }\end{array}$ & $\begin{array}{l}\text { Floral nectar guides discouraged } \\
\text { secondary nectar robbing in bees. }\end{array}$ & $\begin{array}{l}\text { Leonard and Papaj, } \\
\qquad 2011\end{array}$ \\
\hline \multicolumn{5}{|l|}{ Learning } \\
\hline Location learning & Floral traits & $\begin{array}{l}\text { Nectar robbers will learn floral traits } \\
\text { associated with the location of } \\
\text { robbing damage. }\end{array}$ & $\begin{array}{l}\text { Bumble bees primary-robbed flowers } \\
\text { consistently on their left or right sides; } \\
\text { behavior attributed to visual cue of } \\
\text { robbing holes in other flowers (although } \\
\text { social demonstration was not ruled } \\
\text { out). }\end{array}$ & Goulson et al., 2013 \\
\hline Instrumental learning & $\begin{array}{l}\text { Complexity of motor } \\
\text { routines }\end{array}$ & $\begin{array}{l}\text { Robbing behavior will be learned } \\
\text { through trial and error }\end{array}$ & $\begin{array}{c}\text { Exposure to an artificial robbing hole } \\
\text { facilitated primary robbing behavior in } \\
\text { bumble bees. }\end{array}$ & $\begin{array}{l}\text { Leadbeater and } \\
\text { Chittka, } 2008\end{array}$ \\
\hline Transfer and interference & $\begin{array}{l}\text { Plant community } \\
\text { assemblage }\end{array}$ & $\begin{array}{l}\text { Handling tactics that increase } \\
\text { transfer and decrease interference } \\
\text { in a given environment will be } \\
\text { preferred. }\end{array}$ & $\begin{array}{l}\text { Not studied explicitly in nectar robbing } \\
\text { context. }\end{array}$ & $\mathrm{n} / \mathrm{a}$ \\
\hline \multicolumn{5}{|l|}{ Decision making } \\
\hline Previous experience & $\begin{array}{l}\text { Flowering phenology, Plant } \\
\text { community assemblage }\end{array}$ & $\begin{array}{l}\text { Pollinators will choose tactics } \\
\text { based on their prior experience. }\end{array}$ & $\begin{array}{l}\text { Bumble bees randomly assigned to } \\
\text { legitimate visitation or nectar robbing } \\
\text { tended to choose their previously } \\
\text { experienced tactics later. }\end{array}$ & Barker et al., 2018 \\
\hline Risk assessment & $\begin{array}{l}\text { Resource quality, Resource } \\
\text { variability, Hunger state }\end{array}$ & $\begin{array}{l}\text { Pollinators will choose tactics } \\
\text { based on their relative benefit. }\end{array}$ & $\begin{array}{l}\text { Visitors robbed flowers in the wild when } \\
\text { nectar robbing was more efficient than } \\
\text { legitimate visitation. }\end{array}$ & Lichtenberg et al., 2018 \\
\hline Switching between two tactics & $\begin{array}{l}\text { Investment in learning, } \\
\text { Working memory capacity }\end{array}$ & $\begin{array}{l}\text { If nectar robbing is easier to learn or } \\
\text { affected less by working memory } \\
\text { capacity than foraging legitimately, } \\
\text { robbers will tend to switch more } \\
\text { between plant species. }\end{array}$ & $\begin{array}{l}\text { Not studied in the context of tactic } \\
\text { constancy, but floral constancy } \\
\text { literature exists. }\end{array}$ & $\mathrm{n} / \mathrm{a}$ \\
\hline
\end{tabular}

Cognitive processes are listed in the order discussed in the review; we consider multiple levels of analysis non-exhaustively.

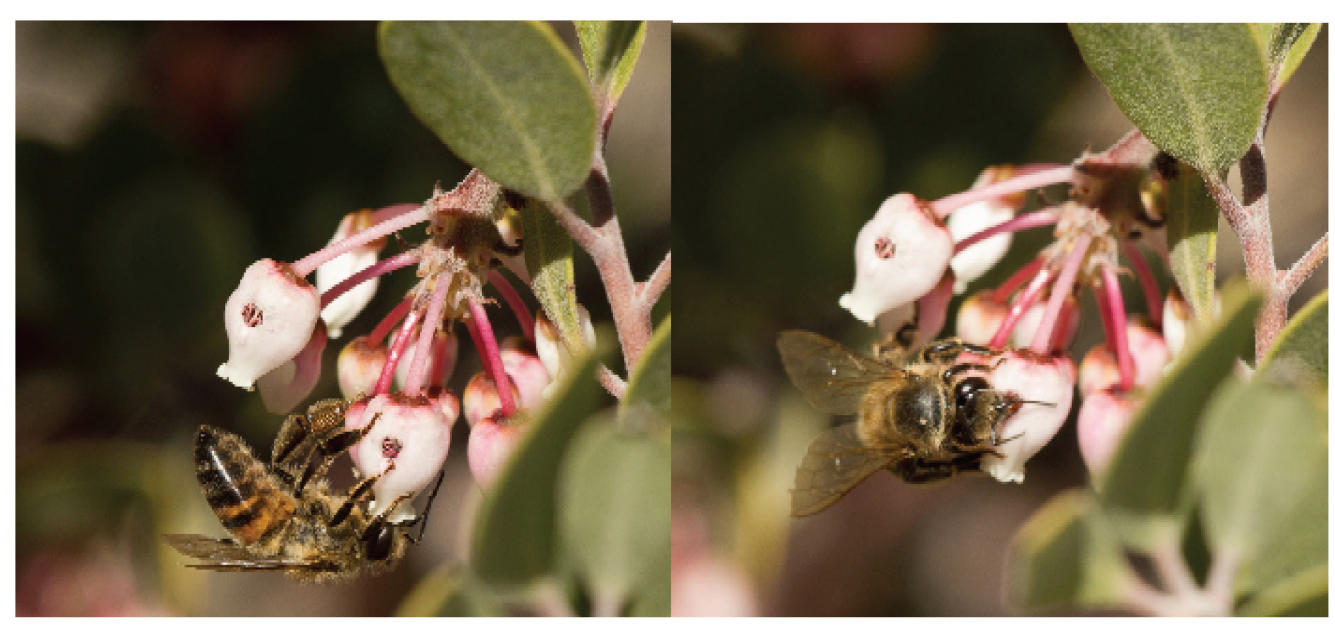

FIGURE 1 | A honey bee (Apis mellifera) using different foraging tactics to consume nectar from a pointleaf manzanita (Arctostaphylous pungens) flower. The bee first uses a legitimate foraging tactic (left) before switching to secondary nectar robbing (right). Photos by Carl Hutter.

terrestris bumble bees consistently show a preference for colors at the blue-violet end of the visual light spectrum, and Bombus spp. are commonly associated with blue-violet flowers in nature (Eidesen et al., 2017). The association can improve bee foraging efficiency, perhaps driving selection for innate biases
(Raine and Chittka, 2007b). Bees show a propensity to orient toward divided patterns. The star-like form of a daisy, generated by its ray flowers, is particularly attractive (Howard et al., 2019). It is not currently known whether nectar robbing differs from legitimate visitation in terms of how individuals express innate 
preferences for floral traits, or whether sensory biases (for color, odor, etc.) drive their foraging behavior in the same way. Drawing from the literature on pollinator sensory ecology, however, we are able to generate hypotheses about the extent to which nectar robbing stems from a different set of sensory responses.

Evaluating sensory biases in the context of nectar robbing requires an understanding of how they develop, function, and evolve. We expect floral signals mediating legitimate visitation to be matched to pollinators' sensory biases, since plants benefit by soliciting visits (Schiestl, 2017). However, except in the case in which robbing is beneficial to the plant (e.g., Maloof and Inouye, 2000), no such match would be expected between biases and the cues used to rob a flower. In fact, we might expect evolution to favor plant traits that conceal robbing sites or that make them less conspicuous to the robber, such as shorter corollas or larger calyces (Irwin et al., 2010). It is therefore reasonable to surmise that nectar robbing emerges in response to a different set of sensory biases than legitimate foraging, and/or that it has evolved from biological processes unrelated to foraging for floral rewards. One such process is mate choice (Schiestl and Johnson, 2013). Bees show innate preferences for dots or small circles contrasted against a background, possibly because these resemble individual mates or aggregations of mates (Van Kleunen et al., 2007; Ellis and Johnson, 2010). Secondary-robbing bees may be innately attracted to robber holes or slits because they resemble such markings. Sensory biases have long been thought to play a role in sexual selection (Dawkins and Guilford, 1996; Fuller et al., 2005), and more recently have been argued to influence foraging decisions (Parachnowitsch et al., 2019), including floral visitation (Schiestl and Johnson, 2013; Schiestl, 2017). A major question, moving forward, is the degree to which non-foraging and foraging sensory biases influence each other, and how selection for sensory biases may act in pollinator populations with different foraging behaviors.

\section{Learning to Rob: Floral Cues and Motor Routines}

Floral visitation, like any behavior, has learned as well as innate components. Learned behavior is generally functional, meaning in this case that, through experience, pollinators improve their ability to collect floral rewards. We expect learning to be an important component of nectar robbing behavior as well. Two basic forms of learning during nectar robbing are particularly pertinent: (1) Learning cues that identify places on flowers suitable for robbing, and (2) learning motor routines that mediate nectar extraction through robbing holes. We first briefly address learning of suitable robbing cues. We then discuss in more detail how motor routines used in robbing might be learned.

Nectar robbers generally perforate flowers, or feed from pre-existing perforations, at the base of a flower, usually near the nectary or where nectar accumulates in flower spurs (Irwin et al., 2010). Therefore, robbers might learn to identify cues associated with the base of the corolla close to where nectar is located through visual, chemical, and/or tactile means. Studies aiming to uncover how individuals learn to rob, although limited, generally point to discrimination learning, defined here as "the formation of associations between different stimuli and corresponding outcomes or behaviors" (Rose and Schmidt, 2012). One interesting implication of this work is that individual foragers may use discrimination learning to associate certain cues with legitimate foraging and others with nectar robbing. This would explain the widespread intraspecific (and sometimes intraindividual) variation in robbing behavior across taxa observed in nature (Richardson and Bronstein, 2012). Such choice discrimination may enable foragers to rob flowers when robbing is beneficial to them but visit flowers legitimately when that behavior carries the higher benefit; for example, when a flower has not completely opened and therefore nectar is better accessed through robbing.

Learning can also account for the use of different motor routines in different contexts, by linking specific stimuli with specific routines. Such learning is directly relevant to the expression of nectar robbing and legitimate visitation, as nectar robbing requires a different set of motor capabilities than legitimate foraging. For example, primary robbing involves exerting enough force on a flower to puncture petal tissue, and both primary and secondary robbing require foragers to orient themselves on the outside of flowers rather than at the opening of the flower. The visitor might learn simply that piercing the corolla with its mouthparts yields a sugar reward. Such learning would be indicative of instrumental learning, in which an action is acquired and shaped by a contingency between the action and the reward (Dickinson, 1994). Many studies of instrumental learning focus on operant conditioning, a procedure in which the experimenter makes the presentation of a reward contingent upon an animal's actions (Chittka and Thomson, 1997). However, these studies generally focus only on legitimate foraging; the motor routines involved in robbing may not be elucidated from them. Therefore, we advocate for more studies that compare and contrast learning legitimate foraging, primary robbing, and secondary robbing.

It is easy to imagine that successfully acquiring nectar via robbing reinforces robbing movements; however, it is also possible that for visitors that can both rob and visit flowers legitimately, robbing reflects in part learning to not visit legitimately if attempts to do so yield little or no nectar. Initial experience with one behavior instead of another may arise by chance and can influence the extent to which a visitor will sample and learn the second behavior (Barker et al., 2018). Innovation (Tebbich et al., 2016) may be involved, wherein bees try out novel motor movements that might facilitate robbing. For secondary robbers, inserting their mouthparts into the already existing hole might be sufficient to initiate robbing; in contrast, primary robbers have to find the right place to make a hole, and then chew/cut that hole. Initiating the additional motor action required for primary robbing has been shown to be hastened by exposure to robber holes: in a lab study, primary robbing behavior took less time to initiate for naïve bees that were exposed to artificial holes compared to those that were not, suggesting a role of social transmission in learning nectar robbing motor routines (Leadbeater and Chittka, 2008). 


\section{Decision-Making Based on Learning and Memory}

Both innate and learned processes give floral visitors the ability to extract food from flowers. Given the array of signals from different flowers that they experience in nature, visitors must then decide which flowers to extract food from, and how. As floral signals vary considerably over space and/or time, decisionmaking can be cumbersome and expensive. In the early stage of learning about a novel plant species, foragers might have to spend time and energy to assess its quality (Grüter and Ratnieks, 2011) and be less efficient in exploiting its nectar (Laverty, 1994). After they have learned to find and use different plant species, limitations on short-term memory capacity might prevent recall of many search images (Goulson, 2000; Raine and Chittka, 2007a; Ishii and Masuda, 2014) or retrieval of many handling routines from long-term memory (Woodward and Laverty, 1992; Dukas, 1995). Therefore, it would benefit foragers to develop cognitive strategies allowing them to cope with an abundance of information.

Many animals use cognitive heuristics and shortcuts to make decisions in a variable environment, which, although they can seem irrational in the traditional economic sense (when considering short-term costs and benefits), likely evolved to allow animals to make sense of a world with too much information to process (Johnson et al., 2013; Marshall et al., 2013; Vasconcelos et al., 2015; Lichtenberg et al., 2020a). Floral visitors assess the available options not just on their absolute costs and benefits, but relative to the other options that are currently available. For example, honey bees' choices between two foraging options have been shown to be influenced by the introduction of a third option, even if it is less rewarding than the first two (Shafir et al., 2002). Similarly, bumble bees that underperformed in twocolor discrimination task were more flexible in sampling a third, novel color (Evans and Raine, 2014). As the nectar-foraging landscape is constantly changing (Lichtenberg et al., 2020a) open flowers are visited by robbing and legitimate foragers, depleting nectar, while flowers continue to open-we would expect foragers to use such cognitive heuristics and shortcuts to decide which flowers to visit. For example, evaluating flowers on their relative, rather than absolute, rewards may result in foragers choosing options that seem to violate economic cost-benefit analysis (Biernaskie et al., 2009).

Experience and risk assessment are two further examples of how cognitive heuristics influence floral foragers' decisions (Chittka et al., 2003). For example, bumble bees' initial experience with either robbing or legitimate visitation, even if serendipitous, discourages them from attempting the tactic they have not experienced (Barker et al., 2018). We can liken this decision to that of a forager choosing between two resource types, one that it has experienced and one that it has not. Furthermore, a forager's decision threshold can change depending on the current availability of the resources (Hodges, 1985), or their variability in quality and/or quantity (Keasar et al., 2013). Floral visitors' decisions are also affected by how risky each option is likely to be, and how the animal assesses the uncertainty of other options (Kacelnik and El Mouden, 2013). The extent to which a forager is risk averse depends on its current hunger state, as well as its perception of fitness consequences of each choice (Chittka et al., 2003; Houston et al., 2014). These physiological and perception factors would affect nectar-robbing decisions if robbing and legitimate visitation do not reliably provide nectar rewards of the same volume or concentration. For example, robbed flowers often have lower nectar volumes and/or higher nectar concentrations than unrobbed flowers (Pleasants, 1983; Newman et al., 2005). When this is the case, a forager might encounter different rewards when secondary robbing vs. when foraging legitimately on a previously unrobbed flower. How the relative risks and rewards of robbing vs. visiting legitimately affect the decision to adopt these behaviors is not known for any system of which we are aware. It is an important area for future research.

For floral visitors potentially able to use either tactic, the conundrum they face over whether and when to adopt legitimate foraging vs. robbing is a problem of task switching. Pollinators that switch frequently between two tasks have been reported to suffer reduced performance on both tasks compared to pollinators conducting only one of the two tasks (Monsell, 2003; Kiesel et al., 2010; Caselli and Chelazzi, 2011). The cost of task switching by insect pollinators has been evaluated both with respect to foraging on flowers with different morphologies (Lewis, 1986; Woodward and Laverty, 1992; Laverty, 1994; Chittka et al., 1999; Goulson, 2000) and to switching between nectar foraging and egg-laying, usually in butterflies (Stanton, 1984; Weiss and Papaj, 2003). We propose that the same considerations of costs can be extended to switching between legitimate foraging and nectar robbing.

Recent studies of tactic constancy of nectar robbers-akin to floral constancy-offer an example of this approach. Floral constancy, the consistent visitation to one species or floral morph even if other equally or more rewarding options are available, is often interpreted as a consequence of costs associated with switching from one option to another (Waser, 1979; Chittka et al., 1999). Costs of switching may pertain to nectar robbing and legitimate visitation. Do floral visitors show tactic constancy (i.e., consistent use of one tactic over another), suggestive of the possibility of costs of task switching? Use of a combination of tactics has been documented at the species level (Johnson et al., 2013; Marshall et al., 2013; Lichtenberg et al., 2020b). Switching between tactics at the individual level has also been reported, although at least sometimes at low frequencies (Richardson and Bronstein, 2012; Richman et al., 2017a). At present, the frequency of switching at the individual level is too poorly explored to draw generalizations. Similarly, we currently know too little about the factors predicting when switching would take place (Bronstein et al., 2017). It is logical to suppose that tactic choice will be governed by the relative gains an individual receives from each food handling tactic (Biernaskie et al., 2009; Lichtenberg et al., 2018). This hypothesis was addressed in a recent study on competition for nectar when standing crop is highly variable. That study found no connection between competition intensity and the probability that an individual would switch tactics (Lichtenberg et al., 2020b).

Since assessing the relative gains of each food handling tactic may require time investment, another hypothesis is that 
organisms exhibit an ontogenetic shift in tactic constancy. Younger individuals may be more likely to switch as they seek and acquire information about different tactics, whereas older individuals may be more likely to settle in on one tactic as they become more efficient over time in one handling tactic, leading to an ontogenetic pattern of shift in tactic constancy. To our knowledge, this hypothesis has not been tested.

Limitation on memory capacities could also play a role in tactic constancy. When animals must learn two motor routines in succession, memory of one sometimes inhibits learning and performance of the other, which is called an interference effect (Bouton, 1993; Dukas, 1995; Bond and Kamil, 1999). For example, even if pollinators can successfully store more than two flower handling motor routines in their long-term memory, retrieving those memories for behavioral execution might be interfered with switching from one motor routine to another (Chittka et al., 1999). Although little or no interference has been shown when pollinators switch among flowers with simple morphologies during foraging (Laverty, 1994; Raine and Chittka, 2007a), switching among flowers with complex/different morphologies yielded increased flower handling time (Woodward and Laverty, 1992; Laverty, 1994; Raine and Chittka, 2007a), suggesting the similarities of flower handling motor routines may affect the degree of interference. In contrast to the interference effect, learning in one context may improve performance in another context, indicative of a transfer effect (Perkins and Salomon, 1992). For example, foragers can learn an appropriate motor routine to exploit nectar from a specific flower type (Laverty, 1980, 1994), which then may be generalized to other, similar flower types, helping to exploit new flower types.

\section{CONSIDERING COGNITION IN PLANT-FOCUSED STUDIES}

Floral visitors express foraging preferences and make decisions, including whether to legitimately forage or to rob nectar, underlaid by a complex suite of sensory and cognitive mechanisms, as discussed above. These behaviors can have profound consequences for plants. While many studies have tested how robbing affects plant fitness, few have considered how the cognitive processes underpinning nectar robbers' decisions may be relevant to their experimental designs. There are some situations in which ignoring robber cognition would have little impact on interpretation of results. For example, if robbers select plants at random to rob and if robbers damage flower reproductive organs when they rob, assigning robbing treatments to plants at random and mimicking robbing damage at realistic levels (e.g., Zhang et al., 2007; Castro et al., 2008; Richman et al., 2017b) should provide an accurate assessment of robbing effects on plant fitness. However, in other cases, a lack of consideration of robber cognition could lead to misinterpretation of findings. For instance, using a randomized experimental approach removes any covariance between plant vigor and robbing levels, for example if robbers select larger or more fecund plants (e.g., Irwin, 2006). Therefore, an experimenter using an artificial robbing approach would need to consider whether they should also try to mimic robbing damage based on behavioral patterns instead of at random. Below, we provide two additional scenarios in which an understanding of the sensory and cognitive processes involved in nectar robbing can inform studies of plant reproduction.

First, it seems unlikely that robbers select flowers and plants to rob at random. Instead, like legitimate floral visitors, robbers likely use floral traits to select flowers and plants to rob (Gélvez-Zúñiga et al., 2018; Wu et al., 2019), and therefore would (1) exhibit sensory and cognitive biases and (2) rely on previous experience, as discussed above. In scenarios where robbers also act as legitimate visitors, either at the individual or population level, it is plausible that similar cognitive processes and constraints mediate how visitors select among flowers in legitimate and robbing visits. This scenario could play out either when foragers use both tactics on the same plant species or if their experience with one plant species carries over to affect behavior at another plant species. In either scenario, plants must contend with visits from both robbers and legitimate visitors based upon the same set of cues, so when robbing reduces plant fitness, they may experience tradeoffs in the attraction of legitimate vs. robbing visits (Gélvez-Zúñiga et al., 2018). Alternatively, if floral signals used by visitors differ when they use legitimate vs. robbing tactics (as may be the case, as discussed above), plants may have a greater opportunity to discourage robbing and encourage legitimate visits, in scenarios where robbing reduces fitness. For instance, legitimate visitation could involve responses to cues at the front of flowers, while robbing tactics may involve greater responses to cues at the side or base of flowers. These differences in acquired stimuli could affect the decision to visit particular flowers and ultimately flower choice depending on the tactic used. Thus, the results of cognitive processes with different stimuli could lead to a scenario in which robbing visits occur on some flowers or plants, but legitimate visits on others, such that robbing could reinforce patterns of pollinator-mediated selection. No study to our knowledge has characterized the underlying cognitive mechanisms that underlie flower choice when visitors rob vs. visit legitimately, and the subsequent implications for plant fitness and patterns of natural selection on floral traits.

Second, the extent to which floral foragers are tactic-constant should determine plant reproductive success. While still not entirely understood, tactic constancy is driven by cognition, and so an understanding of robber cognition will help generate hypotheses about how the behavior is expressed and how it affects plants. As discussed above, evidence is accumulating that floral visitors exhibit tactic constancy, i.e., constancy to one foraging tactic, either legitimate or robbing visits (Bronstein et al., 2017; Lichtenberg et al., 2020b). Consider a forager on a plant species whose flowers it can legitimately visit and pollinate, or else rob and fail to pollinate (reviewed in Irwin et al., 2010; Bronstein et al., 2017). If foragers rob a series of flowers (short-term tactic constancy), punctuated by periodic legitimate (pollinating) visits, such behavior could serve to reduce geitonogamy (within-plant pollen transfer) and increase pollen flow distances and outcrossing as the number of flowers between 
A
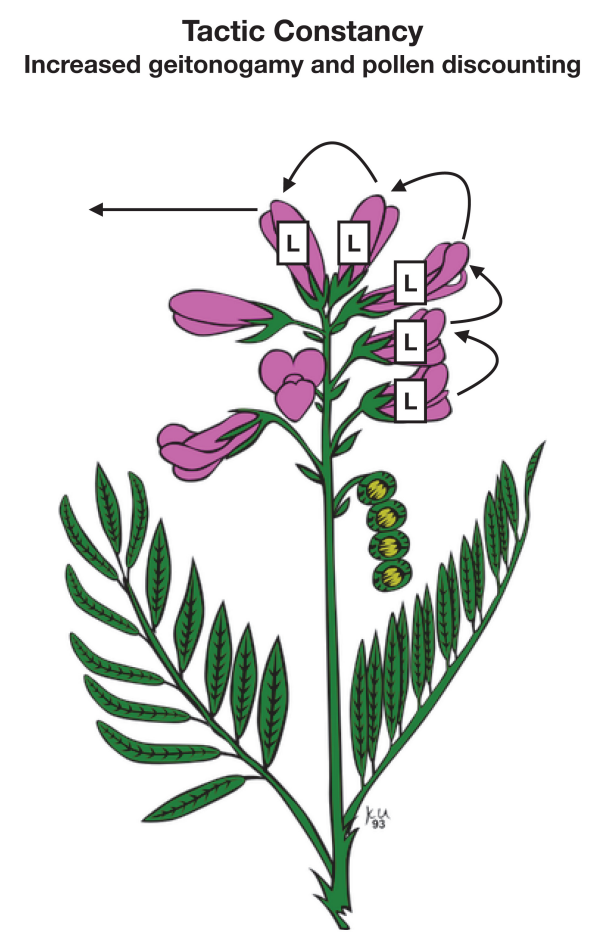

B

\author{
Tactic Switching \\ Decreased geitonogamy and pollen discounting
}

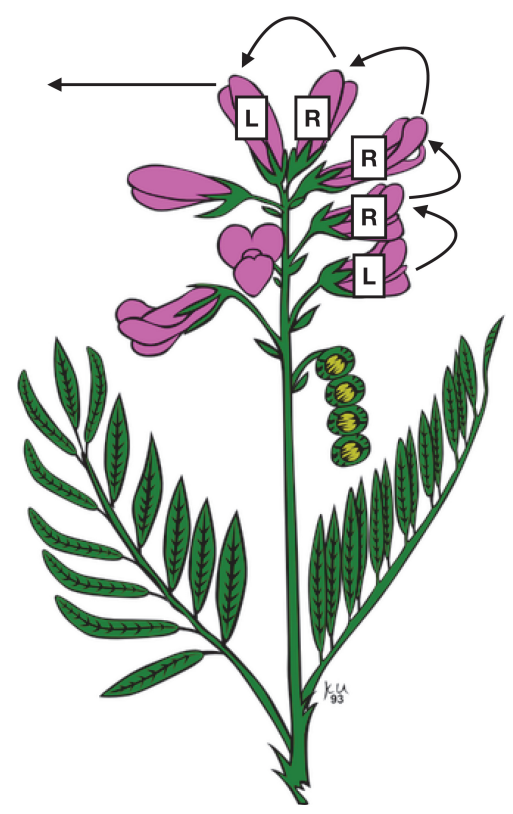

FIGURE 2 | Hypothesized effects of tactic constancy vs. tactic switching on pollen flow. Each panel shows a visitation pattern of a floral forager; flowers labeled "L" receive legitimate foraging visits and flowers labeled "R" receive robbing visits (primary or secondary). Floral visitors that remain constant to legitimate foraging $(\mathbf{A})$ have a higher potential of depositing geitonogamous self-pollen, which can lead to increased pollen discounting. Floral visitors that switch between legitimate foraging and nectar robbing (B) bypass the stigmas of more flowers per plant than a constant legitimate forager, reducing the potential of depositing geitonogamous self-pollen and of pollen discounting. Flower drawing by K. Urban, available under Creative Commons licensing.

two legitimate foraging visits increases (Figure 2). Increased outcrossing has previously been hypothesized to be a potential benefit to plants of being robbed (e.g., Zimmerman and Cook, 1985; Maloof, 2001). However, the proposed mechanism was completely different: it was hypothesized that pollinators would fly further after visiting a robbed flower with lower nectar reward, relative to an unrobbed flower with higher nectar reward, in an effort to escape an unrewarding flower patch. This behavioral pattern would presumably increase pollen flow and outcrossing. In our scenario, tactic constancy, and its underlying cognitive mechanism, indirectly affects pollen flow and outcrossing, a result that would not have been captured by experimentally robbing flowers and recording legitimate visitation. While, as we point out above, tactic constancy has been observed (Bronstein et al., 2017; Lichtenberg et al., 2020b), the degree to which it affects pollen flow and outcrossing remains to be explored.

\section{CONCLUSION}

In many ways, nectar robbing resembles any other floral foraging tactic. Floral visitors use signals and cues provided by flowers, coupled with information about their foraging environment, to make decisions about which flowers to visit and how to extract their rewards. Following this logic, we would expect the basic sensory and cognitive processes underlying nectar robbing to overlap substantially with those underlying legitimate foraging. However, as we have pointed out in this review, the ways in which nectar robbers and legitimate foragers react to stimuli may differ. Furthermore, because the motor routines for each tactic differ, nectar robbers and legitimate foragers may also differ in how they learn flower handling.

Many issues central to our understanding of the cognitive ecology of nectar-robbing remain unexplored. One open question is the extent to which the decision to rob is economically "rational," resulting in a higher net benefit to the forager than other foraging options. As accumulating research, discussed above, reveals that foragers make decisions that violate traditional "rationality" (e.g., context-dependent preferences), we would expect to see this reflected in robbing behavior. Another question is the extent to which robbing motor routines are innate vs. learned. The literature on cognitive ecology and pollination has provided a rich body of work describing innate preferences (sensory biases) for flower color, shape, scent, and reward properties (Schiestl and Johnson, 2013; Schiestl, 2017). Although nectar robbers likely show many of the same preferences in deciding which flowers to visit, how they develop flower handling tactics after deciding on a flower remains largely unknown. Controlled experiments in the laboratory using naïve foragers are one way to begin answering this question. For instance, 
experiments could be designed to test the hypothesis that a primary robbing motor routine develops when a forager encounters flowers that are not fully open or too narrow to enter (Rivera et al., 2006), predicting a higher probability of primary robbing when bees are presented with a high frequency of closed, partially open, or narrow flowers. This experiment could be conducted using captive, naïve bees provided with arrays of closed vs. open flowers or of flowers with narrow vs. broad corollas. In order to distinguish whether development of a motor routine was indicative of learning to rob vs. choosing between two tactics, researchers could compare the degree of trial and error in naïve and experienced bees; if learning to rob, the difference in trial and error between naïve and experienced bees should be greater than if bees are choosing between tactics.

The overwhelming majority of studies on the cognitive ecology of floral visitation, whether in the context of pollination or nectar robbing, have been conducted using bumble bees (Bombus spp.) and honey bees (Apis mellifera), both social species, as study subjects. As we have pointed out, however, the taxonomic breadth of organisms reported to be nectar robbers is high, spanning multiple phyla and classes within phyla. We advocate for broadening the representation of taxa in experimental studies of robbing to match the breadth of species exhibiting robbing behaviors. Recent advances in the laboratory rearing of solitary bee species such as Xylocopa virginica (the Eastern carpenter bee) for experiments in lab, field, or semi-field settings allow researchers to compare and contrast nectar robbing in bees with solitary vs. social life histories (that are likely to have evolved different cognitive processes). Hummingbirds have been well studied in terms of context-dependent decision-making

\section{REFERENCES}

Baracchi, D. (2019). Cognitive ecology of pollinators and the main determinants of foraging plasticity. Curr. Zool. 65, 421-424. doi: 10.1093/cz/zoz036

Barker, J. L., Dornhaus, A., Bronstein, J. L., and Muth, F. (2018). Learning about larceny: experience can bias bumble bees to rob nectar. Behav. Ecol. Sociobiol. 72:68. doi: $10.1007 / \mathrm{s} 00265-018-2478-6$

Belsare, P. V., Sriram, B., and Watve, M. G. (2009). The co-optimization of floral display and nectar reward. J. Biosci. 34, 963-967. doi: 10.1007/s12038-0090110-7

Biernaskie, J. M., Walker, S. C., and Gegear, R. J. (2009). Bumblebees learn to forage like Bayesians. Am. Nat. 174, 413-423. doi: 10.1086/603629

Bond, A. B., and Kamil, A. C. (1999). Searching image in blue jays: facilitation and interference in sequential priming. Anim. Learn. Behav. 27, 461-471. doi: 10.3758/BF03209981

Bouton, M. E. (1993). Context, time, and memory retrieval in the interference paradigms of Pavlovian learning. Psychol. Bull. 114, 80-99. doi: 10.1037/00332909.114.1.80

Bronstein, J. L., Barker, J. L., Lichtenberg, E. M., Richardson, L. L., and Irwin, R. E. (2017). The behavioral ecology of nectar robbing: why be tactic constant? Curr. Opin. Insect Sci. 21, 14-18. doi: 10.1016/j.cois.2017.05.013

Caselli, L., and Chelazzi, L. (2011). Does the macaque monkey provide a good model for studying human executive control? A comparative behavioral study of task switching. PLoS One 6:e21489. doi: 10.1371/journal.pone.0021489

Castro, S., Silveira, P., and Navarro, L. (2008). Consequences of nectar robbing for the fitness of a threatened plant species. Plant Ecol. 199, 201-208. doi: 10.1007/s11258-008-9424-z and risk sensitivity (e.g., Hurly and Oseen, 1999; Morgan et al., 2014), which could be used as the foundation for studies of nectar robbing. In addition, manipulative studies using captive or semi-captive nectar robbing birds, such as those in the genus Diglossa (flowerpiercers, e.g., Schondube and Del Rio, 2003), will be particularly important for expanding beyond insects our understanding of cognition as it relates to nectar robbing. By doing so, we will be able to have a stronger understanding of the generality of nectar robbing behavior, as well as begin to comprehend its evolutionary origins.

\section{AUTHOR CONTRIBUTIONS}

JBa conceived of the idea for the article. All authors contributed to providing content, which was organized and curated by SR.

\section{FUNDING}

Some of the work reported here was supported by grants from the U.S. National Science Foundation (DEB$1354061 / 1641243$ to RI and JBr).

\section{ACKNOWLEDGMENTS}

A. Dornhaus and F. Muth provided key ideas that shaped this article. We thank two reviewers for their valuable feedback on an earlier version of this manuscript.

Chittka, L., and Thomson, J. D. (1997). Sensori-motor learning and its relevance for task specialization in bumble bees. Behav. Ecol. Sociobiol. 41, 385-398. doi: $10.1007 / \mathrm{s} 002650050400$

Chittka, L., and Thomson, J. D. (eds) (2001). Cognitive Ecology of Pollination: Animal Behaviour and Floral Evolution. Cambridge: Cambridge University Press. doi: 10.1017/CBO9780511542268

Chittka, L., Dyer, A. G., Bock, F., and Dornhaus, A. (2003). Bees trade off foraging speed for accuracy. Nature 424:388. doi: 10.1038/424388a

Chittka, L., Thomson, J. D., and Waser, N. M. (1999). Flower constancy, insect psychology, and plant evolution. Naturwissenschaften 86, 361-377. doi: 10 . 1007/s001140050636

Dawkins, M. S., and Guilford, T. (1996). Sensory bias and the adaptiveness of female choice. Am. Nat. 148, 937-942. doi: 10.1086/285964

Dedej, S., and Delaplane, K. (2005). Net energetic advantage drives honey bees (Apis mellifera L) to nectar larceny in Vaccinium ashei Reade. Behav. Ecol. Sociobiol. 57, 398-403. doi: 10.1007/s00265-004-0852-z

Dickinson, A. (1994). "Instrumental conditioning," in Animal Learning and Cognition, ed. N. J. Mackintosh (Amsterdam: Elsevier), 45-79. doi: 10.1016/ B978-0-08-057169-0.50009-7

Dukas, R. (1995). Transfer and interference in bumblebee learning. Anim. Behav. 49, 1481-1490. doi: 10.1016/0003-3472(95)90069-1

Eidesen, P. R., Little, L., Müller, E., Dickenson, K. J. M., and Lord, J. M. (2017). Plant-pollinator interactions affect colonization efficiency: abundance of bluepurple flowers is associated with species richness of bumblebees in the Arctic. Biol. J. Linn. Soc. 121, 150-162.

Ellis, A. G., and Johnson, S. D. (2010). Floral mimicry enhances pollen export: the evolution of pollination by sexual deceit outside of the Orchidaceae. Am. Nat. 176, E143-E151. doi: 10.1086/656487 
Evans, L. J., and Raine, N. E. (2014). Foraging errors play a role in resource exploration by bumble bees (Bombus terrrestris). J. Comp. Physiol. A 200, 475-484. doi: 10.1007/s00359-014-0905-3

Fitch, G., and Vandermeer, J. H. (2020). Light availability influences the intensity of nectar robbery and its effects on reproduction in a tropical shrub via multiple pathways. Am. J. Bot. 107, 1635-1644. doi: 10.1002/ajb2.1559

Fuller, R. C., Houle, D., and Travis, J. (2005). Sensory bias as an explanation for the evolution of mate preferences. Am. Nat. 166, 437-446. doi: 10.1086/444443

Gélvez-Zúñiga, I., Teixido, A. L., Neves, A. C. O., and Fernandes, G. W. (2018). Floral antagonists counteract pollinator-mediated selection on attractiveness traits in the hummingbird-pollinated Collaea cipoensis (Fabaceae). Biotropica 50, 797-804. doi: 10.1111/btp. 12574

Goulson, D. (2000). Are insects flower constant because they use search images to find flowers? Oikos 88, 547-552.

Goulson, D., Park, K. J., Tinsley, M. C., Bussière, L. F., and Vallejo-Marin, M. (2013). Social learning drives handedness in nectar-robbing bumblebees. Behav Ecol. Sociobiol. 67, 1141-1150.

Grüter, C., and Ratnieks, F. L. W. (2011). Flower constancy in insect pollinators: adaptive foraging behaviour or cognitive limitation? Commun. Integr. Biol. 4, 633-636. doi: 10.4161/cib.16972

Hazlehurst, J. A., and Karubian, J. O. (2018). Impacts of nectar robbing on the foraging ecology of a territorial hummingbird. Behav. Process. 149, 27-34. doi: 10.1016/j.beproc.2018.01.001

Hodges, C. M. (1985). Bumble bee foraging: the threshold departure rule. Ecology 66, 179-187. doi: $10.2307 / 1941318$

Houston, A. I., Fawcett, T. W., Mallpress, D. E. W., and McNamara, J. M. (2014). Clarifying the relationship between prospect theory and risk-sensitive foraging theory. Evol. Hum. Behav. 35, 502-507. doi: 10.1016/j.evolhumbehav.2014.06. 010

Howard, S. R., Shrestha, M., Schramme, J., Garcia, J. F., Avarguès-Weber, A., Greentree, A. D., et al. (2019). Honeybees prefer novel insect-pollinated flower shapes over bird-pollinated flower shapes. Curr. Zool. 65, 457-465.

Hurly, T. A., and Oseen, M. D. (1999). Context-dependent, risk-sensitive foraging preferences in wild rufous hummingbirds. Anim. Behav. 58, 59-66. doi: 10. 1006/anbe.1999.1130

Inouye, D. W. (1980). The terminology of floral larceny. Ecology 61, 1251-1253. doi: $10.2307 / 1936841$

Irwin, R. E. (2006). The consequences of direct versus indirect species interactions to selection on traits: pollination and nectar robbing in Ipomopsis aggregata. Am. Nat. 167, 315-328. doi: 10.1086/499377

Irwin, R. E., and Maloof, J. E. (2002). Variation in nectar robbing over time, space, and species. Oecologia 133, 525-533. doi: 10.1007/s00442-002-1060-z

Irwin, R. E., Bronstein, J. L., Manson, J. S., and Richardson, L. (2010). Nectar robbing: ecological and evolutionary perspectives. Annu. Rev. Ecol. Evol. Syst. 41, 271-292. doi: 10.1146/annurev.ecolsys.110308.120330

Ishii, H. S., and Masuda, H. (2014). Effect of flower visual angle on flower constancy: a test of the search image hypothesis. Behav. Ecol. 25, 933-944. doi: 10.1093/beheco/aru071

Johnson, D. D. P., Blumstein, D. T., Fowler, J. H., and Haselton, M. G. (2013). The evolution of error: error management, cognitive constraints, and adaptive decision-making biases. Trends Ecol. Evol. 28, 474-481. doi: 10.1016/j.tree.2013. 05.014

Kacelnik, A., and El Mouden, C. (2013). Triumphs and trials of the risk paradigm. Anim. Behav. 86, 1117-1129. doi: 10.1016/j.anbehav.2013.09.034

Keasar, T., Motro, U., and Shmida, A. (2013). Temporal reward variability promotes sampling of a new flower type by bumblebees. Anim. Behav. 86, 747-753. doi: 10.1016/j.anbehav.2013.07.010

Kiesel, A., Steinhauser, M., Wendt, M., Falkenstein, M., Jost, K., Philipp, A. M., et al. (2010). Control and interference in task switching-a review. Psychol. Bull. 136, 849-874. doi: $10.1037 / \mathrm{a} 0019842$

Laverty, T. M. (1980). The flower-visiting behaviour of bumble bees: floral complexity and learning. Can. J. Zool. 58, 1324-1335. doi: 10.1139/z80-184

Laverty, T. M. (1994). Bumble bee learning and flower morphology. Anim. Behav. 47, 531-545. doi: 10.1006/anbe.1994.1077

Leadbeater, E., and Chittka, L. (2008). Social transmission of nectar-robbing behaviour in bumble-bees. Proc. Biol. Sci. 275, 1669-1674. doi: 10.1098/rspb. 2008.0270
Leonard, A. S., and Papaj, D. R. (2011). 'X' marks the spot: the possible benefit of nectar guides to bees and plants. Funct. Ecol. 25, 1-9.

Lewis, A. C. (1986). Memory constraints and flower choice in Pieris rapae. Science 232:863. doi: $10.1126 /$ science. 232.4752 .863

Lichtenberg, E. M., Irwin, R. E., and Bronstein, J. L. (2018). Costs and benefits of alternative food handling tactics help explain facultative exploitation of pollination mutualisms. Ecology 99, 1815-1824. doi: 10.1002/ecy.2395

Lichtenberg, E. M., Heiling, J. M., Bronstein, J. L., and Barker, J. L. (2020a). Noisy communities and signal detection: why do foragers visit rewardless flowers? Philos. Trans. R. Soc. B 375:20190486. doi: 10.1098/rstb.2019.0486

Lichtenberg, E. M., Richman, S. K., Irwin, R. E., and Bronstein, J. L. (2020b). Competition for nectar resources does not affect bee foraging tactic constancy. Ecol. Entomol. 45, 904-909. doi: 10.1111/een.12866

Lihoreau, M., Dubois, T., Gomez-Moracho, T., Kraus, S., Monchanin, C., and Pasquaretta, C. (2019). "Putting the ecology back into insect cognition research," in Advances in Insect Physiology, ed. R. Jurenka (Amsterdam: Elsevier), 1-25. doi: 10.1016/bs.aiip.2019.08.002

Maloof, J. E. (2001). The effects of a bumble bee nectar robber on plant reproductive success and pollinator behavior. Am. J. Bot. 88, 1960-1965. doi: 10.2307/ 3558423

Maloof, J. E., and Inouye, D. W. (2000). Are nectar robbers cheaters or mutualists? Ecology 81, 2651-2661. doi: 10.1890/0012-96582000081[2651:ANRCOM]2.0. $\mathrm{CO} ; 2$

Marshall, J. A. R., Trimmer, P. C., Houston, A. I., and McNamara, J. M. (2013). On evolutionary explanations of cognitive biases. Trends Ecol. Evol. 28, 469-473. doi: 10.1016/j.tree.2013.05.013

Monsell, S. (2003). Task switching. Trends Cogn. Sci. 7, 134-140. doi: 10.1016/ S1364-6613(03)00028-7

Morgan, K. V., Hurly, T. A., and Healy, S. D. (2014). Individual differences in decision making by foraging hummingbirds. Behav. Process. 109, 195-200. doi: 10.1016/j.beproc.2014.08.015

Newman, D. A., Thomson, J. D., and Ranta, E. (2005). Effects of nectar robbing on nectar dynamics and bumblebee foraging strategies in Linaria vulgaris (Scrophulariaceae). Oikos 110, 309-320.

Parachnowitsch, A. L., Manson, J. S., and Sletvold, N. (2019). Evolutionary ecology of nectar. Ann. Bot. 123, 247-261. doi: 10.1093/aob/mcy132

Perkins, D. N., and Salomon, G. (1992). "Transfer of learning," in International Encyclopedia of Eduction, Eds T. N. P. Torsten Husen (Oxford: Pergamon Press), 6452-6457.

Pleasants, J. M. (1983). Nectar production patterns in Ipomopsis aggregata Polemoniaceae). Am. J. Bot. 70, 1468-1475. doi: 10.1002/j.1537-2197.1983. tb10850.x

Pyke, G. H. (2016). Floral nectar: pollinator attraction or manipulation? Trends Ecol. Evol. 31, 339-341. doi: 10.1016/j.tree.2016.02.013

Raine, N. E., and Chittka, L. (2007b). The adaptive significance of sensory bias in a foraging context: floral colour preferences in the bumblebee Bombus terrestris. PLoS One 2:e556. doi: 10.1371/journal.pone.000 0556

Raine, N. E., and Chittka, L. (2007a). Flower constancy and memory dynamics in bumblebees (Hymenoptera: Apidae: Bombus). Entomol. Gen. 29, 179-199. doi: $10.1127 /$ entom.gen/29/2007/179

Richardson, L., and Bronstein, J. L. (2012). Reproductive biology of pointleaf manzanita (Arctostaphylos pungens) and the pollinator-nectar robber spectrum. J. Pollinat. Ecol. 9, 115-123.

Richman, S. K., Irwin, R. E., and Bronstein, J. L. (2017a). Foraging strategy predicts foraging economy in a facultative secondary nectar robber. Oikos 126, 1250-1257. doi: 10.1111/oik.04229

Richman, S. K., Irwin, R. E., Nelson, C. J., and Bronstein, J. L. (2017b). Facilitated exploitation of pollination mutualisms: fitness consequences for plants. J. Ecol. 105, 188-196. doi: 10.1111/1365-2745.12657

Rivera, A. J., Hernandez, E. J., and Nates-Parra, G. (2006). Morphological constraints and nectar robbing in three Andean bumble bee species (Hymenoptera, Apidae, Bombini). Caldasia 28, 111-114.

Rojas-Nossa, S. V., Sánchez, J. M., and Navarro, L. (2016). Nectar robbing: a common phenomenon mainly determined by accessibility constraints, nectar volume and density of energy rewards. Oikos 125, 1044-1055. doi: 10.1111/oik. 02685 
Rose, J., and Schmidt, R. (2012). "Discrimination learning model," in Encyclopedia of the Sciences of Learning, ed. N. M. Seel (Boston, MA: Springer US), 10131015. doi: 10.1007/978-1-4419-1428-6_343

Schiestl, F. P. (2017). Innate receiver bias: its role in the ecology and evolution of plant-animal interactions. Annu. Rev. Ecol. Evol. Syst. 48, 585-603. doi: 10.1146/annurev-ecolsys-110316-023039

Schiestl, F. P., and Johnson, S. D. (2013). Pollinator-mediated evolution of floral signals. Trends Ecol. Evol. 28, 307-315. doi: 10.1016/j.tree.2013.01.019

Schondube, J. E., and Del Rio, C. M. (2003). Concentration-dependent sugar preferences in nectar-feeding birds: mechanisms and consequences: concentration-dependent sugar preferences. Funct. Ecol. 17, 445-453. doi: 10. 1046/j.1365-2435.2003.00749.x

Shafir, S., Waite, T. A., and Smith, B. H. (2002). Context-dependent violations of rational choice in honeybees (Apis mellifera) and gray jays (Perisoreus canadensis). Behav. Ecol. Sociobiol. 51, 180-187. doi: 10.1007/s00265-001-0 420-8

Stanton, M. L. (1984). Short-term learning and the searching accuracy of egg-laying butterflies. Anim. Behav. 32, 33-40. doi: 10.1016/S0003-3472(84)80321-8

Tebbich, S., Griffin, A. S., Peschl, M. F., and Sterelny, K. (2016). From mechanisms to function: an integrated framework of animal innovation. Philos. Trans. R. Soc. B 371:20150195. doi: 10.1098/rstb.2015. 0195

van der Kooi, C. J., Vallejo-Marín, M., and Leonhardt, S. D. (2021). Mutualisms and (a)symmetry in plant-pollinator interactions. Curr. Biol. 31, R91-R99. doi: 10.1016/j.cub.2020.11.020

Van Kleunen, M., Nänni, I., Donaldson, J. S., and Manning, J. C. (2007). The Role of beetle marks and flower colour on visitation by monkey beetles (Hopliini) in the Greater Cape Floral Region, South Africa. Ann. Bot. 100, 1483-1489. doi: $10.1093 / \mathrm{aob} / \mathrm{mcm} 256$

Vasconcelos, M., Monteiro, T., and Kacelnik, A. (2015). Irrational choice and the value of information. Sci. Rep. 5:13874. doi: 10.1038/srep1 3874

Waser, N. M. (1979). Pollinator availability as a determinant of flowering time in ocotillo (Fouquieria splendens). Oecologia 39, 107-121. doi: 10.1007/ BF00346001

Webb, B. (2012). Cognition in insects. Philos. Trans. R. Soc. B 367, 2715-2722. doi: $10.1098 /$ rstb.2012.0218
Weiss, M. R., and Papaj, D. R. (2003). Colour learning in two behavioural contexts: how much can a butterfly keep in mind? Anim. Behav. 65, 425-434. doi: 10. 1006/anbe.2003.2084

Woodward, G. L., and Laverty, T. M. (1992). Recall of flower handling skills by bumble bees: a test of Darwin's interference hypothesis. Anim. Behav. 44, 1045-1051. doi: 10.1016/S0003-3472(05)80316-1

Wu, Y., Zhang, Z. Q., and Li, Q. J. (2019). Nectar robbers influence the traitfitness relationship of Primula secundiflora. Plant Biol. J. 21, 967-974. doi: 10.1111/plb. 13000

Zhang, Y.-W., Robert, G. W., Wang, Y., and Guo, Y.-H. (2007). Nectar robbing of a carpenter bee and its effects on the reproductive fitness of Glechoma longituba (Lamiaceae). Plant Ecol. 193, 1-13.

Zhang, Y.-W., Zhao, J.-M., Yang, C.-F., and Gituru, W. R. (2011). Behavioural differences between male and female carpenter bees in nectar robbing and its effect on reproductive success in Glechoma longituba (Lamiaceae). Plant Biol. 13, 25-32. doi: 10.1111/j.1438-8677.2009.00279.x

Zimmerman, M., and Cook, S. (1985). Pollinator foraging, experimental nectarrobbing and plant fitness in Impatiens capensis. Am. Midl. Nat. 113, 84-91. doi: $10.2307 / 2425350$

Conflict of Interest: The authors declare that the research was conducted in the absence of any commercial or financial relationships that could be construed as a potential conflict of interest.

Publisher's Note: All claims expressed in this article are solely those of the authors and do not necessarily represent those of their affiliated organizations, or those of the publisher, the editors and the reviewers. Any product that may be evaluated in this article, or claim that may be made by its manufacturer, is not guaranteed or endorsed by the publisher.

Copyright $\odot 2021$ Richman, Barker, Baek, Papaj, Irwin and Bronstein. This is an open-access article distributed under the terms of the Creative Commons Attribution License (CC BY). The use, distribution or reproduction in other forums is permitted, provided the original author(s) and the copyright owner(s) are credited and that the original publication in this journal is cited, in accordance with accepted academic practice. No use, distribution or reproduction is permitted which does not comply with these terms. 